\title{
Evaluating Total Lymphocyte Counts as a Substitute for CD4 Counts in the Follow Up of AIDS Patients
}

\author{
Ana Luiza Dias Angelo ${ }^{1}$, Camila Dias Angeloㄹ, Alex José Leite Torres ${ }^{1}$, André Maurício Costa Ramos ${ }^{1}$, \\ Márcia Lima ${ }^{2}$ Eduardo Martins Netto ${ }^{1,3}$ and Carlos Brites ${ }^{1,3}$ \\ ${ }^{1}$ Infectious Diseases Research Unit, Professor Edgard Santos Hospital, Federal University of Bahia; ${ }^{2}$ Hematology Service, Professor Edgard \\ Santos Hospital, Federal University of Bahia; ${ }^{3}$ Infectious Diseases Foundation of Bahia; Salvador, BA, Brazil
}

\begin{abstract}
This study evaluated total lymphocyte count (TLC) as a substitute marker for $\mathrm{CD}^{+}$cell counts to identify patients who need prophylaxis against opportunistic infection (CD4 $<200$ cells $/ \mathrm{mm}^{3}$ ) and patients with CD4 $<350$ cells $/ \mathrm{mm}^{3}$ (Brazilian threshold value of CD4 count to define AIDS). We evaluated TLC and CD4 ${ }^{+}$cells count of 1,174 HIVinfected patients, in Salvador, Brazil, from May 2003 to September 2004. CD4 ${ }^{+}$cell counts were performed by flow cytometry, and TLC was measured with an automated hematological counter. The mean CD4 count was 430 cells/

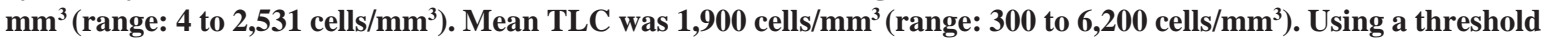
value of 1,000 cells $/ \mathrm{mm}^{3}$ for TLC, the positive predictive value (PPV) was $77 \%$ for CD4 $<200 \mathrm{cells} / \mathrm{mm}^{3}$, but the sensitivity was only $29 \%$, while the negative predictive value (NPV) was $88 \%$, with $98 \%$ specificity. Similar findings were observed for CD4 count $<350$. Using the same threshold value of 1,000 cells $/ \mathrm{mm}^{3}$ for TLC, sensitivity was $14 \%$, and specificity 99\% (PPV= 94\%; NPV=62\%). In 70/1,510 (5\%) of the samples the sum of CD4 and CD8 cell counts was greater than the TLC and in $27 \%(419 / 1,510)$ this sum was below $65 \%$ of the TLC. TLC has a high specificity to identify patients for prophylaxis, but a quite low sensitivity. It is not useful as an alternative to $\mathrm{CD}^{+}{ }^{+} \mathrm{T}$-cell counts as a marker in HIV-infected patients.
\end{abstract}

Key-Words: Lymphocyte counts, CD4 counts, AIDS.

According to UNAIDS, more than 45 million people have been infected by the human immunodeficiency virus (HIV) since the first case was described in 1981 . Over $90 \%$ of HIVinfected people live in developing countries. The AIDS epidemic has resulted in a tremendous cost in terms of loss of lives and life-quality worldwide, especially in Africa, where $70 \%$ of deaths from HIV-1 infection have occurred [1].

There is an emerging consensus that the HIV epidemic in the developing world requires treatment with antiretroviral drugs [2]. The benefits of highly-active-antiretroviral therapy (HAART) are well documented. However, due to its high cost, few people in developing countries currently have access to antiretroviral therapy (ART). Recent initiatives of the World Health Organization (WHO) for scaling up ART in resourcelimited settings are resulting in an increasing number of HIVinfected patients having access to ART. In well-resourced settings, the decision to initiate ART is based predominantly on the presence of HIV-related symptoms and on CD4+ T-cell count, according to the current guidelines [3].

Absolute CD4 ${ }^{+}$T-cell counts and $\mathrm{CD} 4^{+}$percentages have constituted the mainstay criteria for monitoring progression in HIV-1 infected patients. CD4 ${ }^{+} \mathrm{T}$-cell counts $<200 \mathrm{cell} / \mathrm{mm}^{3}$ or a $\mathrm{CD} 4^{+}$percentage $<20 \%$ is associated with an increased risk for Pneumocystis jiroveci pneumonia or infection with other opportunistic pathogens. Prophylaxis against $P$. jiroveci

Received on 13 February 2007; revised 19 August 2007.

Address for correspondence: Dr. Carlos Brites. Hospital Universitário Prof. Edgard Santos, $6^{\circ}$ andar. Rua João das Botas SN, Canela. Salvador, Bahia, Brazil. Zip code: 40110-160. Phone-55-71-32354901. Fax: 55-71-32472756. E-mail: crbrites@ufba.br.

The Brazilian Journal of Infectious Diseases 2007;11(5):466-470. (C) 2007 by The Brazilian Journal of Infectious Diseases and Contexto Publishing. All rights reserved. is recommended when the $\mathrm{CD}^{+}{ }^{+}$T-cell count falls to $<200$ cell $/ \mathrm{mm}[3,4]$.

Monitoring individuals with HIV infection/AIDS requires the use of expensive tools, which are not readily available in resource-limited settings [5]. The identification of laboratory tests that help the clinician to predict progression is useful not only to monitor the patients' disease evolution but also to define the right time to initiate treatment [6]. In April 2002, the WHO recommended the use of absolute lymphocyte count as an alternative marker when a $\mathrm{CD} 4^{+}$cell count is not available or is not affordable: a total lymphocyte count of less than 1,000-1,200 lymphocytes $/ \mathrm{mm}^{3}$ could be used as a threshold value to initiate antiretroviral therapy [5]. WHO has suggested that total lymphocyte counts (TLC) could work as a potential marker for immunosuppression whenever CD4 counts are unavailable, because TLC is easily obtained from routine complete blood cell counts by multiplying the percentage of lymphocytes by the white-blood-cell count [7].

One challenge for using TLC for predicting the disease stage is that it does not linearly decrease over time during HIV infection, but rather there is a period of stability, followed by a faster decay that precedes clinically-defined AIDS. Furthermore, TLC can also be affected by a number of other factors that are not associated with disease progression [2].

Absolute lymphocyte count as well as CD4 cell counts can be affected by other infections, such as HTLV-I/II. The higher CD4 ${ }^{+}$lymphocyte counts observed in HIV/HTLV coinfection do not provide immunological benefits, and may rather reflect HTLV-associated non-specific lymphocyte proliferation [8,9]. This may also introduce a bias in the evaluation of such patients in areas where co-infection by these agents is frequent [10].

The available evidence is controversial regarding the use of TLC as a marker for AIDS staging. Several studies have 
demonstrated a good correlation between $\mathrm{CD}^{+}{ }^{+} \mathrm{T}$-cell count and the total lymphocyte count (TLC) in HIV-1 infected patients. However, others have showed no correlation between TLC and CD4 ${ }^{+}$cell counts.

We evaluated the usefulness of TLC as a marker for staging HIV disease, for initiating antiretroviral therapy (CD4 > 350 cells $/ \mathrm{mm}^{3}$, Brazilian limit to define AIDS), or for prophylaxis against opportunist infections $\left(\mathrm{CD} 4<200\right.$ cells $/ \mathrm{mm}^{3}$ ) in $\mathrm{HIV}^{+}$ individuals in Salvador, Bahia, a Brazilian city with sociodemographic characteristics that resemble African cities.

\section{Materials and Methods}

This prospective observational study was conducted at the AIDS outpatient clinics of Hospital Universitário Prof. Edgard Santos (HUPES), Federal University of Bahia. All patients attended at the Retroviruses Laboratory, and who were evaluated with routine CD4/8 cell counts, were invited to participate in the study. All patients (older than 18 years) were asked to provide written informed consent before entering the study. The protocol was approved by the HUPES research ethics committee.

After obtaining written informed consent, immunological evaluations were performed. To determine TLC and CD4 ${ }^{+} \mathrm{T}-$ cell counts, blood samples were drawn into Vacutainer tubes with EDTA; $5 \mathrm{~mL}$ samples of blood were taken from the patients, and the samples were analyzed in the same day. All samples were collected between 8:00 and 10:00 AM to avoid circadian variation [11]. TLCs were counted with a hematological counter (ADVIA 60, Bayer, Leverkusen, Germany). The T-cell subset was determined using a flow cytometer (FACScalibur, Becton Dickinson Immunocytometry Systems, Franklin Lakes, USA) and three-color monoclonal antibodies (CD3 - peridinin chlorophyll protein [PerCP], CD8 - fluorescein isothiocyanate [FITC] and CD4 - phycoerythrin [PE]) according to the manufacturer's instructions. The absolute and percentage CD4 ${ }^{+}$T-cell counts were automatically calculated with flowcytometer software (MultiSET). HTLV I and II seropositivity were determined by a positive enzyme-linked immunosorbent assay, confirmed by Western blot (BioMérieux, Boxtel, Holanda). Viral load was determined by NASBA technology (NucliSens HIV-1 QT, Organon, Durham, USA). All results were entered into a database.

We enrolled 1,174 patients who had visited the clinic between May 2003 and September 2004 in this study. Demographic data, such as age and gender, were recorded. The patients were divided into two groups:

- HIV-infected patients on treatment $(\mathrm{N}=1,104)$

- HIV-infected patients without previous antiretroviral therapy $(\mathrm{N}=70)$.

Sensitivity, specificity, and likelihood ratios with 95\% confidence intervals (CIs) of various cutoff points of the TLC to predict an absolute CD4 ${ }^{+}$T-cell count $<200$ cells $/ \mathrm{mm}^{3}$, < 350 cells $/ \mathrm{mm}^{3}, \mathrm{CD}^{+}$percentage $<20 \%$ and $<15 \%$, were calculated. Spearman-rank correlations were calculated for TLC and CD4 ${ }^{+} \mathrm{T}$-cell counts, CD4 ${ }^{+}$percentage and $\mathrm{CD} 8^{+} \mathrm{T}-$ cell counts, and to compare numbers of $\mathrm{CD} 4^{+} \mathrm{T}$-cells and CD8 ${ }^{+}$ T-cells. Correlations were calculated for the whole group as well as in groups stratified by CD $4^{+}$T-cell counts $(<200$ cells/ $\mathrm{mm}^{3}, 200$ to 500 cells $/ \mathrm{mm}^{3}$, and $\geq 500$ cells $/ \mathrm{mm}^{3}$ ), and CD4 ${ }^{+} \mathrm{T}-$ cell counts $<350$ cell $/ \mathrm{mm}^{3}$ or $\geq 350$ cells $/ \mathrm{mm}^{3}$.

All analyses were performed using SPSS 11.0 for Windows statistical software.

\section{Results}

Overall, 1,510 paired TLC and CD4 ${ }^{+}$T-cell counts from 1,174 patients were analyzed to determine the correlation between TLC and CD4 ${ }^{+}$T-cell counts and to find out whether TLC can be used to predict CD4 ${ }^{+}$T-cell counts in a clinical setting.

Among the 1,174 patients enrolled, 721 (61\%) were male. The age ranged from 18 to 82 years (mean: 39 years). The serology for HTLV I and II disclosed 1,125 (96\%) seronegative subjects and 49 (4\%) seropositives. A total of 1,140 (94\%) patients had previously received antiretroviral therapy, and 70 (6\%) were drug naïve.

Most of the patients (74.9\%) had only one evaluation during the period of study, 25\% had two or three evaluations and only one was evaluated four times.

Among 1,510 patients observed, $16.5 \%$ had CD4 $4^{+}$T-cell counts $<200$ cells $/ \mathrm{mm}^{3}, 50 \%$ had counts between 200 and 500 cells $/ \mathrm{mm}^{3}$, and $33.5 \%$ had counts of $\geq 500$ cells $/ \mathrm{mm}^{3}$. The CD4 ${ }^{+}$ T-cell percentage was $<20 \%$ and $<15 \%$ in $26.5 \%$ and $15 \%$ of observations, respectively. Almost all (99.8\%) of patients with less than $200 \mathrm{CD}^{+}$cells $/ \mathrm{mm}^{3}$ also had less than $15 \% \mathrm{CD}^{+}$ cells. A total of $41.5 \%$ the subjects fulfilled the Brazilian criteria to define AIDS (CD4 ${ }^{+}$T-cell count $<350$ cells $/ \mathrm{mm}^{3}$ ).

Spearman-rank correlations between TLC and CD4 $4^{+}$-cells, $\mathrm{CD}^{+}$percentage and $\mathrm{CD}^{+} \mathrm{T}$-cells are summarized in Table 1. There was a strong correlation between TLC and CD4 ${ }^{+}$T-cell count ( $r=0.581$ ) within the group, but it weakened considerably when the patients were stratified into groups according to their CD4 ${ }^{+}$T-cell counts. Correlations between TLC and $\mathrm{CD}^{+} \mathrm{T}$-cells for the whole group, as well as for the subgroups, are depicted in Figure 1. No significant correlation ( $\mathrm{r}=-0.019)$ was detected between TLC and CD4 ${ }^{+}$ cell percentages for the whole group. Interestingly, when the observations were stratified according to CD4 ${ }^{+}$T-cell count, a strong negative correlation emerged. Conversely, a strong positive correlation $(\mathrm{r}=0.763)$ was demonstrated between TLC and the CD8 ${ }^{+}$cell counts for the whole group. A weak correlation was also found between $\mathrm{CD} 4^{+}$and $\mathrm{CD}^{+}$ T-cells $(r=0.280)$.

When we used a threshold value of $1,700 \mathrm{cell} / \mathrm{mm}^{3}$, we obtained a maximal combination of sensitivity (76.3\%), specificity (65.2\%), and NPV (93.1\%), but the PPV was only $31.1 \%$ for a CD4 cell count $<200$ cells $/ \mathrm{mm}^{3}$. The same limit gave maximal combined sensitivity (59.4\%), and specificity (75.8\%), for a CD4 cell count $\leq 350$ cells $/ \mathrm{mm}^{3}$ (Tables 2 and 3 ).

A TLC of $<1,700$ cells $/ \mathrm{mm}^{3}$ had a sensitivity of only $45.8 \%$ to detect patients with a $\mathrm{CD}^{+}$percentage $<20 \%$ and a 
Table 1. Spearmen rank correlation between total lymphocyte count (TLC) and CD4+ T-cell, CD4 ${ }^{+}$T-cell percentage and CD8 ${ }^{+}$Tcell counts

\begin{tabular}{|c|c|c|c|c|}
\hline TLC (/mm³) & $\mathbf{N}$ & CD4 ${ }^{+}$T-cell count $\left(/ \mathrm{mm}^{3}\right)$ & $\mathrm{CD4}^{+}$T-cell percentage $\left(/ \mathrm{mm}^{3}\right)$ & $\mathrm{CD8}^{+}$T-cell count $\left(/ \mathrm{mm}^{3}\right)$ \\
\hline \multicolumn{5}{|c|}{ HIV-infected patients in treatment group } \\
\hline All patients & 1412 & $0.580 *$ & -0.017 & $0.768^{*}$ \\
\hline$<200$ & 239 & $0.417 *$ & $-0.141^{*}$ & $0.796 *$ \\
\hline $200-500$ & 710 & $0.240 *$ & $-0.606^{*}$ & $0.796 *$ \\
\hline$\geq 500$ & 463 & $0.379 *$ & $-0.512 *$ & $0.756^{*}$ \\
\hline \multicolumn{5}{|c|}{ HIV-infected patients without previous antiretroviral therapy group } \\
\hline All patients & 98 & $0.610^{*}$ & -0.042 & $0.671^{*}$ \\
\hline$<350$ & 32 & $0.530 *$ & -0.065 & $0.811^{*}$ \\
\hline$\geq 350$ & 66 & $0.432^{*}$ & $-0.447 *$ & $0.646^{*}$ \\
\hline
\end{tabular}

TLC=total lymphocyte count. *Correlação significante $(\mathrm{p}<0.001)$.

Table 2. Combined sensitivity, specificity, positive predictive value, negative predictive value of total lymphocyte counts for absolute CD4 ${ }^{+}$T-lymphocyte counts less than 200 cell $/ \mathrm{mm}^{3}$

\begin{tabular}{|c|c|c|c|c|c|}
\hline TLC (cells/mm $\mathbf{m m}^{3}$ ) & $\mathbf{N}$ & Sensitivity (\%) & Specificity (\%) & PPV (\%) & NPV (\%) \\
\hline$\leq 1,000$ & 90 & 29.0 & 98.3 & 77.8 & 87.1 \\
\hline$\leq 1,200$ & 196 & 46.5 & 92.8 & 57.1 & 89.4 \\
\hline$\leq 1,500$ & 422 & 62.2 & 76.8 & 35.5 & 90.8 \\
\hline$\leq 1,700$ & 591 & 76.3 & 65.2 & 31.1 & 93.1 \\
\hline$\leq 2,000$ & 863 & 88.8 & 44.6 & 24.8 & 95.1 \\
\hline$\leq 2,200$ & 1004 & 92.9 & 33.4 & 22.3 & 95.8 \\
\hline$\leq 2,500$ & 1159 & 95.0 & 20.6 & 19.8 & 95.3 \\
\hline
\end{tabular}

TLC=total lymphocyte count; PPV=predictive positive value; NPV=negative predictive value. $95 \%$ Confidence interval.

Table 3. Combined sensitivity, specificity, positive predictive value, negative predictive value of total lymphocyte counts for identification of an absolute CD4+ T lymphocyte count less than 350 cell $/ \mathrm{mm}^{3}$

\begin{tabular}{|c|c|c|c|c|c|}
\hline TLC (cells/mm³) & $\mathbf{N}$ & Sensitivity (\%) & Specificity (\%) & PPV (\%) & NPV (\%) \\
\hline$\leq 1,000$ & 4 & 9.4 & 98.5 & 75.0 & 69.1 \\
\hline$\leq 1,200$ & 9 & 25.0 & 98.5 & 88.9 & 73.0 \\
\hline$\leq 1,500$ & 19 & 43.8 & 92.4 & 73.7 & 77.2 \\
\hline$\leq 1,700$ & 35 & 59.4 & 75.8 & 57.3 & 79.4 \\
\hline$\leq 2,000$ & 62 & 93.8 & 51.5 & 48.4 & 94.4 \\
\hline$\leq 2,200$ & 71 & 93.8 & 37.9 & 42.3 & 92.6 \\
\hline$\leq 2,500$ & 82 & 96.9 & 22.7 & 37.8 & 93.8 \\
\hline
\end{tabular}

Table 4. Ability of total lymphocyte count (TLC) to predict CD4 ${ }^{+}$T-cell percentages of $<20 \%$ and $<15 \%$

\begin{tabular}{|c|c|c|c|c|}
\hline \multirow[b]{2}{*}{ TLC (cells/mm } & \multicolumn{2}{|c|}{$<20 \%$ CD4 } & \multicolumn{2}{|c|}{$<15 \%$ CD4 } \\
\hline & Sensitivity (\%) & Specificity (\%) & Sensitivity (\%) & Specificity (\%) \\
\hline$\leq 1,000$ & 12.8 & 96.1 & 18.5 & 95.9 \\
\hline$\leq 1,200$ & 21.0 & 89.1 & 28.8 & 88.6 \\
\hline$\leq 1,500$ & 32.3 & 71.9 & 36.6 & 72.1 \\
\hline$\leq 1,700$ & 45.8 & 60.1 & 49.8 & 60.0 \\
\hline$\leq 2,000$ & 62.0 & 39.0 & 66.1 & 39.6 \\
\hline$\leq 2,200$ & 70.0 & 28.4 & 72.7 & 29.1 \\
\hline$\leq 2,500$ & 79.0 & 16.7 & 80.2 & 17.5 \\
\hline
\end{tabular}

TLC=total lymphocyte count. 
Figure 1. Distribution of TLC x CD4 T-cell counts of HIV-infected patients. (a) in treatment and (b) without previous antiretroviral therapy.

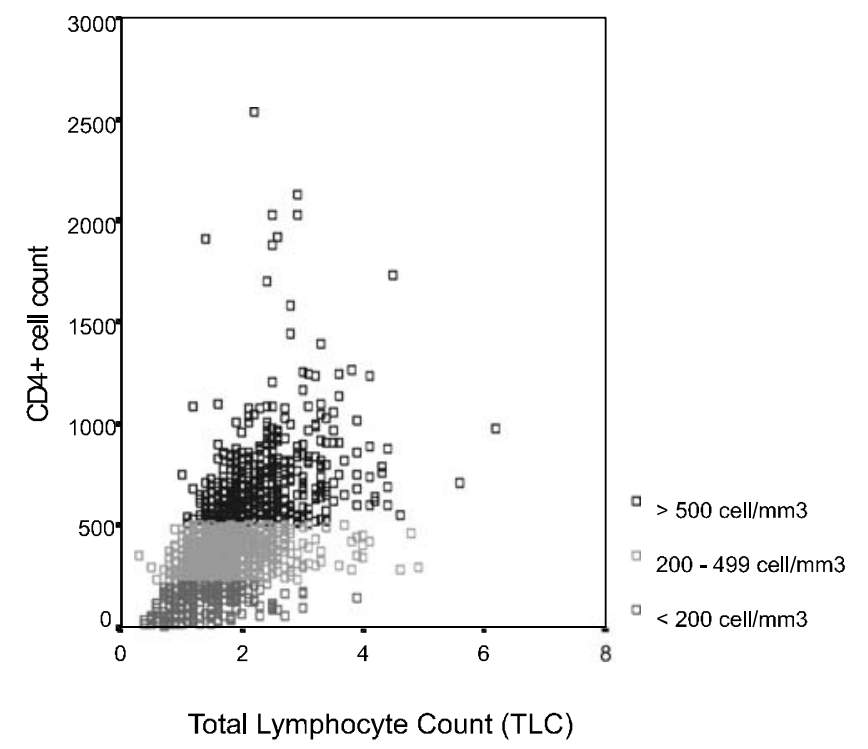

specificity of $60.1 \%$. The same threshold value provided a sensitivity of $49.8 \%$ and a specificity of $60 \%$ to predict patients with $\mathrm{CD} 4^{+}$percentage $<15 \%$ (Table 4 ).

When the TLC cutoff value was lowered, specificity increased at the cost of decreased sensitivity. We did not detect any difference in the correlation between $\mathrm{CD}^{+} \mathrm{T}$-cell count and TLC when patients were compared according to HTLV-serology results.

\section{Discussion}

As early as 1988, it was concluded that an absolute CD4 threshold of 200 cells $/ \mathrm{mm}^{3}$ could define when prophylaxis treatment should be initiated to reduce the risk of Pneumocystis jiroveci pneumonia. Other early studies identified the importance of an absolute CD4 cutoff point of 50-100 cells $/ \mathrm{mm}^{3}$ for increased risk of Mycobacterium avium bacteremia, toxoplasmosis, and cytomegalovirus infections. The benefit of prophylaxis against opportunistic infections (OIs) in HIV-positive patients with CD4 count $<200$ cells $/ \mathrm{mm}^{3}$ has been well documented. More recently, evidence has emerged that early prophylaxis, when the CD4 count reaches $<350$ cells $/ \mathrm{mm}^{3}$, significantly reduces other bacterial and parasitic infections common in HIV-positive patients, such as bacterial pneumonia, isosporiasis and salmonellosis $[7,12]$.

However, sophysticated equipment is needed for lymphocyte subpopulation analysis, such as flow cytometers, which are not available in most laboratories in resource-limited settings [13]. We found that TLC, a widely-available and inexpensive parameter, cannot be used to replace CD4 count as a routine marker of immune status and for defining the best time to initiate OI prophylaxis.

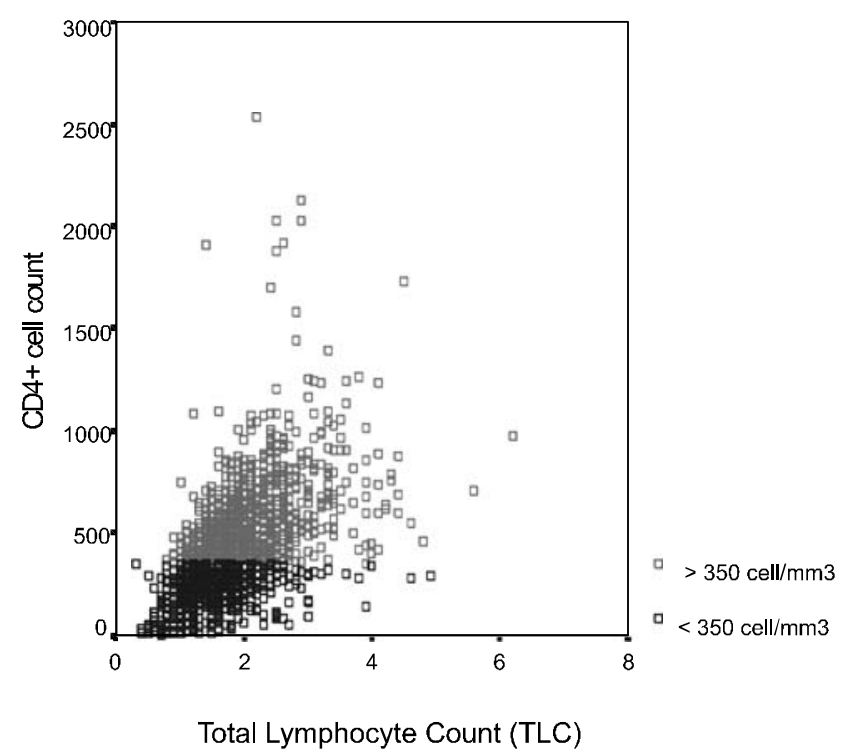

Several studies have suggested that TLC can be used to predict the $\mathrm{CD}^{+}{ }^{+} \mathrm{T}$-cell count in HIV/AIDS patients. Fournier and Sosenko [14] indicated that the total lymphocyte count has clinical utility as a predictor of AIDS stage. In addition, in a study involving 828 patients (2,866 observations) in the United States, Blatt et al. [15] found that TLC was a useful indicator of significant immunosuppression, defined as a CD4 ${ }^{+}$ T-cell count $<200$ cells $/ \mathrm{mm}^{3}$. Kumarasamy et al. [7] reported that TLC could serve as a low-cost tool for identifying a patient at risk for $\mathrm{OI}$ and to determine when to initiate prophylaxis in resource-constrained settings. Contrary to other studies, we found that TLC is not a good predictor of the $\mathrm{CD}^{+}$T-cell count, as also found by Akinola et al. [5] and Vand Der Ryst et al. [4].

We found a good correlation between TLC and CD4 counts with the Spearman rank test $(r=0.581)$. However, it was weaker than that observed in India [7] ( $\mathrm{r}=0.744)$, England [16] ( $\mathrm{r}=0.76)$, North America [14,15] $(\mathrm{r}=0.77)$ and South Africa [4] $(\mathrm{r}=0.70)$. Other authors also obtained a stronger correlation between these parameters [Jacobson et al. [17] (r=0.68); Badri and Wood [3] ( $\mathrm{r}=0.61)$; and Pascale et al. [6] ( $\mathrm{r}=0.68)$ ]. In contrast, Akinola et al. [5] demonstrated a poor correlation $(r=0.43)$, when comparing all findings.

Kumarasamy et al. [7] found that a TLC $<1,400$ cells $/ \mathrm{mm}^{3}$ had a 76\% PPV, and a 86\% NPV; it was 73\% sensitive and 88\% specific for a CD4 count $<200$ cells $/ \mathrm{mm}^{3}$. They also found that a TLC $<1,700$ cells $/ \mathrm{mm}^{3}$ had a $86 \%$ PPV, 69\% NPV, and was $70 \%$ sensitive and $86 \%$ specific for a CD4 count $<350$ cells/ $\mathrm{mm}^{3}$. Similarly, Blatt et al. [15] demonstrated that a TLC $<1,400$ cells $/ \mathrm{mm}^{3}$ was $80 \%$ sensitive and $90 \%$ specific for a CD4 count $<200$ cells/mm 3 . 
Post et al. [18] evaluated TLC and CD4 ${ }^{+}$T-cell counts of $831 \mathrm{HIV} / \mathrm{AIDS}$ patients from South Africa as predictors of developing AIDS or death. They concluded that a TLC of $<$ $1,250 \mathrm{cell} / \mathrm{mm}^{3}$ and a CD4 ${ }^{+} \mathrm{T}$-cell count of $<200$ cells $/ \mathrm{mm}^{3}$ were equal predictors of disease progression and could be used as a cutoff for starting prophylaxis.

We found that with a threshold value of 1,700 cells $/ \mathrm{mm}^{3}$ for TLC, the positive predictive value was only 31.1\% for CD4 $<200$ cells $/ \mathrm{mm}^{3}$, and the sensitivity was $76.3 \%$. The negativepredictive value was $93.1 \%$, with a specificity of $65.2 \%$. A better result was observed for the limit of 350 cells $/ \mathrm{mm}^{3}$, which presented the best correlation with a TLC of 1,700 cells $/ \mathrm{mm}^{3}$ ( $\mathrm{SE}=59.4 \%, \mathrm{SPE}=75.8 \%)$.

Using the limit of 1,700 cells $/ \mathrm{mm}^{3}$ for the TLC, only $7 \%$ of patients under treatment would have less than 200 cells $/ \mathrm{mm}^{3}$ of CD4. This means that such a limit could be used to safely detect severely-immunodepressed patients, candidates for prophylaxis against OIs. Using this threshold value as a preliminary screening, an estimated economy of up to $60 \%$ of the resources to monitor HIV patients could be achieved.

We found no correlation between TLC and the CD4 T-cell percentages in this group of patients. In fact, a rather strong negative correlation emerged when the observations were stratified by CD4 counts. This is similar to what was found by Beck et al. [16], Blatt et al. [15] and Van Der Ryst et al. [4].

We did not find strong correlations based on the four indexes that were measured (PPV, NPV, sensitivity and specificity). Altogether, these results indicate that although a statistical correlation exists between TLC and the CD4 ${ }^{+}$T-cell counts, TLC is not a good predictor of CD4 $4^{+} \mathrm{T}$-cell counts. In agreement with Akinola et al. [5], we conclude that TLC would not be a safe marker for CD4 ${ }^{+}$T-cell counts in HIV-infected patients. However, it could be used as a preliminary screening to define the population at highest risk for development of OIs, and to indicate the need for prophylaxis. A threshold value of 1,700 lymphocytes was the most useful to identify such patients.

\section{References}

1. UNAIDS/WHO. Global Report 2004. 2004.

2. Gange S.J.L.B., Phair J., Riddler S.A., et al. Rapid declines in total lymphocyte count and hemoglobin in HIV infection begin at $\mathrm{CD}_{4}$ lymphocyte counts that justify antiretroviral therapy. AIDS 2003;17:119-31.

3. Badri M., Wood R. Usefulness of total lymphocyte count in monitoring higly active antiretroviral therapy in resourcelimited settings. AIDS 2003;17: 541-45.
4. Van Der Ryste K. M., Joubert G., Steyn M., et al. Correlation among total lymphocyte count. absolute $\mathrm{CD}_{4}^{+}$count. and $\mathrm{CD}_{4}^{+}$ percentage in a group of HIV-1 infected South African patients. J Acquir Immune Defic Syndr and Human Retrovirology 1998;19(3): 238-44.

5. Akinola O.O., Adediran I.A., Onayemi O., et al. The search for a predictor of $\mathrm{CD}_{4}$ cell count continues: Total lymphocyte count is not a substitute for CD cell count in the management of HIVinfected individuals in a resource-limited setting. Clin Infect Dis 2004;39: 579-81.

6. Pascale J.M.I.M., Contreras P., Gomez B., et al. Immunological markers od disease progression in patients infected with the Human Immunodeficiency Virus. Clin and Diagnostic Laboratory Immunol 1997;4(4): 474-7.

7. Kumarasamy N.M. A., Flanigan T.P., Hemalatha R., et al. Total lymphocyte count (TLC) is a useful tool for the timing of opportunistic infection prophylaxis in India and other resourceconstrained countries. JAIDS 2002;31:378-83.

8. Guimarães M.L.B.F., Telles P.R., Galvão-Castro B., et al. Retrovirus infections in a sample of injecting drug users in Rio de Janeiro City. Brazil: prevalence of HIV-1 subtypes. and co-infection with HTLV-I/II. J Clin Virol 2001;21:143-51.

9. Willy R.J.S.C., Macalino G.E., Rich J.D. Long-term non-progression of HIV-1 in a patient coinfected with HTLV-II. Diagn Microbiol Infect Dis 1999;35: 269-70.

10. Schechter M.Z.R., Machado L.L., Pinto M.E., et al. Predicting $\mathrm{CD}_{4}$ counts in HIV-infected Brazilian individuals: a model based on the World Health Organization Staging System. JAIDS 1994;7:163-8.

11. Malone J.L., Gray G.C., Wagner K.F., et al. Sources of variability in repeated T-helper lymphocyte counts from HIV-1 type 1infected patients: total lymphocytes count fluctuations and diurnal cycle are important. J Acquir Immune Defic Syndr 1990;3:144-51.

12. Gebo K.A., Keruly J.C., Moore R.D. Absolute $\mathrm{CD}_{4}$ vs. $\mathrm{CD}_{4}$ percentage for predicting the risk of opportunistic illness in HIV infection. J Acquir Immune Defic Syndr 2004;36:1028-33.

13. WHO. Scaling up antiretroviral therapy in resource-limited settings: treatment guidelines for a public health approach. Geneva, 2003.

14. Fournier A.M., Sosenko J.M. The relationship of total lymphocyte count to $\mathrm{CD}_{4}$ lymphocyte counts in patients infected with Human Immunodeficiency Virus. Am J Med Sci 1992;304(2): 79-82.

15. Blatt S.P., Butzin C.A., Hendrix C.W., Lucey D.R. Total lymphocyte count as a predictor of absolute $\mathrm{CD}_{4}^{+}$count and $\mathrm{CD}_{4}^{+}$percentage in $\mathrm{HIV}$-infected persons. JAMA 1993;269(5):622-6.

16. Beck E.J., Gompels M.M., Pinching A.J. Correlation between total and $\mathrm{CD}_{4}$ lymphocyte counts in HIV infection: not making the good an enemy of the not so perfect. Int J STD AIDS 1996;7(6): 422-8.

17. Jacobson M.A., Khayam-Bashi H., Deeks S.G., et al. Absolute or total lymphocyte count as a marker for the $\mathrm{CD}_{4} \mathrm{~T}$ lymphocyte criterion for initiating antiretroviral therapy.” AIDS 2003;17(6): 917-9.

18. Post F.A. Maartens G. CD and total lymphocyte counts as predictors of HIV disease progression. Q J Med 1996;89:505-8. 